ARTICLE

\title{
Boron-doped sodium layered oxide for reversible oxygen redox reaction in $\mathrm{Na}$-ion battery cathodes
}

Yu-Jie Guo 1,2,4, Peng-Fei Wang (1,2,4, Yu-Bin Niu1,2,4, Xu-Dong Zhang1,2, Qinghao Li (1) 2,3, Xiqian Yu (D) 2,3,

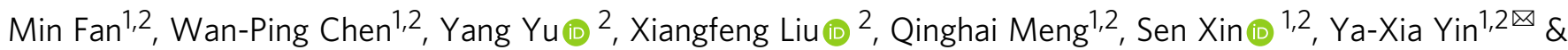
Yu-Guo Guo (iD) 1,2网

$\mathrm{Na}$-ion cathode materials operating at high voltage with a stable cycling behavior are needed to develop future high-energy $\mathrm{Na}$-ion cells. However, the irreversible oxygen redox reaction at the high-voltage region in sodium layered cathode materials generates structural instability and poor capacity retention upon cycling. Here, we report a doping strategy by incorporating light-weight boron into the cathode active material lattice to decrease the irreversible oxygen oxidation at high voltages (i.e., $>4.0 \mathrm{~V}$ vs. $\mathrm{Na}^{+} / \mathrm{Na}$ ). The presence of covalent $\mathrm{B}-\mathrm{O}$ bonds and the negative charges of the oxygen atoms ensures a robust ligand framework for the $\mathrm{NaLi}_{1 / 9} \mathrm{Ni}_{2 / 9} \mathrm{Fe}_{2 / 9} \mathrm{Mn}_{4 / 9} \mathrm{O}_{2}$ cathode material while mitigating the excessive oxidation of oxygen for charge compensation and avoiding irreversible structural changes during cell operation. The B-doped cathode material promotes reversible transition metal redox reaction enabling a room-temperature capacity of $160.5 \mathrm{mAh} \mathrm{g}^{-1}$ at $25 \mathrm{~mA} \mathrm{~g}^{-1}$ and capacity retention of $82.8 \%$ after 200 cycles at $250 \mathrm{~mA} \mathrm{~g}^{-1}$. A $71.28 \mathrm{mAh}$ single-coated lab-scale Na-ion pouch cell comprising a pre-sodiated hard carbon-based anode and B-doped cathode material is also reported as proof of concept.

\footnotetext{
${ }^{1}$ CAS Key Laboratory of Molecular Nanostructure and Nanotechnology, CAS Research/Education Center for Excellence in Molecular Sciences, Beijing National Laboratory for Molecular Sciences, Institute of Chemistry, Chinese Academy of Sciences (CAS), Beijing, People's Republic of China. ${ }^{2}$ University of Chinese Academy of Sciences, Beijing, People's Republic of China. ${ }^{3}$ Beijing National Laboratory for Condensed Matter Physics, Institute of Physics, CAS, Beijing, People's Republic of China. ${ }^{4}$ These authors contributed equally: Yu-Jie Guo, Peng-Fei Wang, Yu-Bin Niu. \email: yxyin@iccas.ac.cn; ygguo@iccas.ac.cn
} 
$\mathrm{N}$ a-ion batteries (NIBs) have been recognized as sustainable solutions to alleviate the resource anxiety of Li-based electrochemical energy storage mainly from sufficient and low-cost sodium raw materials ${ }^{1,2}$. The growing proliferation of robust layered cathode and carbon anode materials has been intensively reported in the last few years. However, the practical implementation of NIBs faced the issue of lower specific energy due to the relatively heavier and less-reducing potential of $\mathrm{Na}$ compared with Li. Specifically, the Cost-Per-kWh of NIBs should be reduced to increase their market competitiveness against Liion batteries (LIBs). To achieve the goal, a feasible strategy is to improve the specific energy and energy density at the cell level. As for the cathode active material, it is required to be reversibly operated at a high voltage and with a large $\mathrm{Na}^{+}$extraction. Anion redox reaction that occurs during high voltage desodiation of layered oxide cathodes offers an avenue to realizing highenergy-density NIBs as it provides an additional capacity by storing charges on both transition metal cations and oxygen anion.

The sodium storage mechanism has been intensively proposed on the key points to motivate the anionic redox that reported in Li-rich compounds from the last two decades ${ }^{3-8}$. Ceder and coworkers proposed the origin of anionic redox in Li-rich and cation-disordered oxides ${ }^{5}$ : the formation of $\mathrm{Li}-\mathrm{O}-\mathrm{Li}$ interactions function as the impetus to trigger oxygen redox due to the weak overlap between $\mathrm{O} 2 p$ and $\mathrm{Li} 2 s$ orbitals, thus favoring the $\mathrm{O} 2 p$ band approximate to the Fermi level and facilitating the oxygen redox reaction. Such a similar situation has been observed in $\mathrm{Na}$ rich and $\mathrm{Na}$-deficient layered oxides ${ }^{9-14}$. These formed $\mathrm{Na}-\mathrm{O}-\mathrm{Na}, \mathrm{Na}-\mathrm{O}-\mathrm{Li}, \mathrm{Na}-\mathrm{O}-\mathrm{Mg}$ interactions are generally considered to effectively trigger oxygen redox, due to the formation of nearly non-bonding state oxygen ${ }^{10,15,16}$. The as-triggered anionic (oxygen) redox processes, combined with cationic redox reaction, enable the staggering capacity increases of layered compounds. However, layered oxides involving oxygen redox reaction commonly suffer from the irreversible oxygen loss from the lattice upon charged to high voltage $(>4.0 \mathrm{~V})$, which eventually results in structural degradation and poor electrochemical performance ${ }^{17,18}$. In addition, the irreversible oxygen release at the surface of layered compounds accelerates the decomposition of electrolyte, which is gradually accumulated on the surface of cathodes, thereby yielding the thick and resistive cathode electrolyte interphase (CEI), and thus resulting in sluggish $\mathrm{Na}^{+}$ transfer kinetics ${ }^{19}$. Therefore, suppressing irreversible oxygen release upon deep desodiaton is crucial for constructing high-capacity cathode materials and actuating the development of NIBs.

Typical improvement strategies by lowering the operation voltage, or reinforcing the metal-oxygen bond via coating and doping are used to suppress oxygen release. While lowering the operation voltage intends to avoid the occurrence of anion redox, it also accounts for dramatically reduced specific energy and energy density of cathode as both $\mathrm{Na}$-storage capacity and voltage are concurrently decreased. This incurs a dilemma in the research of NIBs: the tradeoff between high-voltage electrochemical stability and specific energy and energy density of cathode material. Inert surface coating of metal oxide $\left(\mathrm{Al}_{2} \mathrm{O}_{3}, \mathrm{MgO}\right)^{20,21}$ or metal phosphate $\left(\mathrm{NaPO}_{3}, \beta-\mathrm{NaCaPO}_{4}\right)^{17,22}$ were utilized to stabilize the crystal structure through suppressing surface irreversible phase transformation from irreversible oxygen redox reaction. Alternatively, the doping of inactive cations $\left(\mathrm{Ti}^{4+}, \mathrm{Se}^{6+}, \mathrm{Nb}^{5+}\right)^{23-25}$ is used to increase the oxygen binding energy effectively ${ }^{26}$, alleviating the irreversible oxygen redox reaction and promoting the stability of crystal structure $27-29$. However, it is still challenging to achieve a highly homogenous coating layer on the surface of cathode particles. Doping of heavy inactive metal ions inevitably leads to the reduced specific capacity of cathode $\mathrm{c}^{30-32}$, for instance, it will cause a capacity decrement of ca. $7.3 \%$ by introducing 5 atom. $\%$ of $\mathrm{Zn}^{2+}$ dopant into the lattice of $\mathrm{Na}_{0.833}\left[\mathrm{Li}_{0.25} \mathrm{Mn}_{0.75}\right] \mathrm{O}_{2}$ compound, and $16.0 \%$ by 10 atom. $\%$ of $\mathrm{Ti}^{4+}$ dopant in the $\mathrm{Na}_{0.72} \mathrm{Li}_{0.24} \mathrm{Mn}_{0.76} \mathrm{O}_{2}$ compound according to the previous works (Supplementary Table 1) ${ }^{13,33}$.

With this perspective, doping light-weight element with strong oxygen bond might be a promising strategy to suppress reversible oxygen redox and maintain a minor capacity decrease synchronously. Several light-weight elements have been used as dopants to promote the electrochemical performance of layered oxides which solely undergo the cationic redox even being charged to a very high voltage of $4.6 \mathrm{~V}$ vs. $\mathrm{Na}^{+} / \mathrm{Na}$. For instance, $\mathrm{Li}$ has been introduced into layered oxide $\mathrm{Na}_{0.9} \mathrm{Ni}_{0.3} \mathrm{Mn}_{0.4} \mathrm{Fe}_{0.3} \mathrm{O}_{2}$ to mitigate the $\mathrm{Ni}^{3+}$ Jahn-Teller distortion and prevent the loss of active transition-metal ions ${ }^{34}$. Boron has also been studied as a cathode dopant for $\mathrm{Li}$-ion and $\mathrm{Na}$-ion batteries. In the previous work by Vaalma et al., they reported that B-doping helps to stabilize the cationic redox of $\mathrm{P} 2$-type $\mathrm{Na}_{2 / 3} \mathrm{MnO}_{2}$ cathode material, but with complex phase transition and fast capacity degradation at high voltage $^{35}$. It should be noted that the boron owns the highest binding energy with oxygen among the previously reported elemental dopants $\left(809 \mathrm{~kJ} \mathrm{~mol}^{-1}\right.$ for $\mathrm{B}-\mathrm{O}, \sim 666.5 \mathrm{~kJ} \mathrm{~mol}^{-1}$ for $\mathrm{Ti}-\mathrm{O}, \leq 250 \mathrm{~kJ} \mathrm{~mol}^{-1}$ for $\mathrm{Zn}-\mathrm{O}$ bond $)^{36}$. The high binding energy of $\mathrm{B}-\mathrm{O}$ bonds makes it capable of suppressing the loss of lattice oxygen. $\mathrm{Li}$ et al. reported $\mathrm{B}$-doping could tune the electronic structure through the lowered $\mathrm{O} 2 p$ band top, thus enhancing the stability of oxygen in Li-rich layered cathodes ${ }^{37,38}$.

In this work, we report a doping strategy by incorporating light-weight boron into $\mathrm{O} 3-\mathrm{NaLi}_{1 / 9} \mathrm{Ni}_{2 / 9} \mathrm{Fe}_{2 / 9} \mathrm{Mn}_{4 / 9} \mathrm{O}_{2}$ to suppress the irreversible oxygen release as charging to $>4.0 \mathrm{~V}$. We reveal, from density functional calculations, that the light-weight boron dopant forms a strong-covalent $\mathrm{B}-\mathrm{O}$ bond with adjacent $\mathrm{O}$ atoms, making $\mathrm{O}$ atom electronically more negative to resist excessive oxidation during high-voltage charge compensation via anion redox. The combined analysis of operando X-ray diffraction experiments, X-ray absorption spectroscopy, and differential electrochemical mass spectrometry experimentally demonstrates that the irreversible oxygen release from the lattice at the deep desodiated state is effectively suppressed, accompanying with good structural stability. Interestingly, the light-weight B-doping triggers a more cationic redox reaction to donate an extra capacity, resulting in about a $10.1 \%$ increment in capacity compared with the control material. The B-doped O3-type $\mathrm{NaLi}_{1 / 9} \mathrm{Ni}_{2 / 9} \mathrm{Fe}_{2 /}$ ${ }_{9} \mathrm{Mn}_{4 / 9} \mathrm{~B}_{1 / 50} \mathrm{O}_{2}$ (NLNFMB) exhibits a higher reversible capacity of $160.5 \mathrm{~mA} \mathrm{~h} \mathrm{~g}^{-1}$ at $0.1 \mathrm{C}\left(25 \mathrm{~mA} \mathrm{~g}^{-1}\right)$ and cycling stability with $82.8 \%$ after 200 cycles at $1 \mathrm{C}\left(250 \mathrm{~mA} \mathrm{~g}^{-1}\right)$ in a half cell, compared with that of the undoped pristine NLNFM. The resultant hard carbon||NLNFMB full cell delivers a specific energy of up to $224 \mathrm{Wh} \mathrm{kg}^{-1}$ based on the total mass of cathode and anode active materials. This research demonstrates the prospect of light-weight boron doping for NIBs technology that could suppress irreversible oxygen release and increase the capacity synchronously. Much more stable and high-capacity layered oxides with oxygen redox could be further designed through lightweight element doping strategy.

\section{Results}

Theoretical calculation of the boron-doped oxide compounds. $\mathrm{O} 3-\mathrm{NaLi}_{1 / 9} \mathrm{Ni}_{2 / 9} \mathrm{Fe}_{2 / 9} \mathrm{Mn}_{4 / 9} \mathrm{O}_{2}$ (NLNFM) that is expected to have anion redox with the formation of $\mathrm{Na}-\mathrm{O}-\mathrm{Li}$ interaction, was targeted for boron doping strategy. The TM arrangement in NLNFM is displayed in Supplementary Fig. 1 and Table 2. To figure out the detailed position of boron doping in layered NLNFM, the energy of two configurations with tetrahedral and 


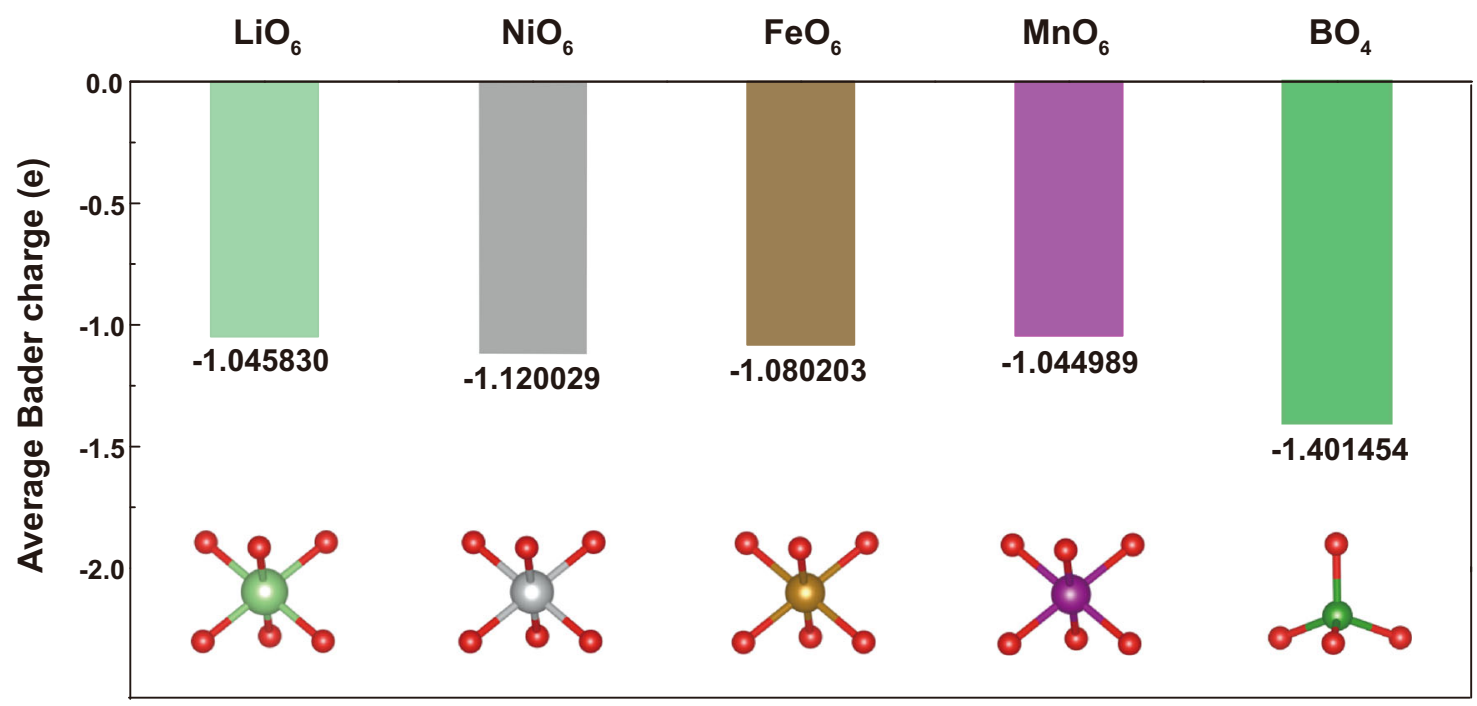

Fig. 1 Bader charge analysis. Average Bader charge of the $\mathrm{O}$ atoms in $\mathrm{MO}_{6}$ octahedron $(\mathrm{M}=\mathrm{Ni} / \mathrm{Fe} / \mathrm{Mn} / \mathrm{Li})$ and in $\mathrm{BO}_{4}$ tetrahedron.

trigonal boron doping sites were calculated, respectively 37,39 . The lowest energy is achieved for the B surrounded by $\mathrm{Li}-\mathrm{Fe}-\mathrm{Mn}$ in tetrahedral interstitial sites (Supplementary Table 3). Bader charge analysis was further employed to disclose the influence of B-doping on the NLNFM structure (Fig. 1, the detailed data are summarized in Supplementary Table 4). One can clearly see that the average charge around the $\mathrm{O}$ atoms between the $\mathrm{BO}_{4}$ octahedron in the $\mathrm{B}$-doped NLNFMB is more negative than those between the $\mathrm{LiO}_{6}, \mathrm{NiO}_{6}, \mathrm{FeO}_{6}, \mathrm{MnO}_{6}$ octahedron in NLNFM by an average extra charge of ca. -0.3 e. This demonstrates that each $\mathrm{B}-\mathrm{O}$ bond introduces a more negative valence charge for $\mathrm{O}$ atom, which could ensure the robust $\mathrm{O}$ ligand framework, thus resisting excessive oxidation during high-voltage charge. The calculated more negative charge around the $\mathrm{O}$ atoms between the $\mathrm{BO}_{4}$ octahedron in the B-doped NLNFMB is consistent with the previous report that 0.02 boron per formula for Li-rich oxides can lower the top of the $\mathrm{O} 2 p$ band, thus enhancing oxygen stability ${ }^{37}$. In addition, we calculated the $\mathrm{O}$ vacancy formation energy for the B-doped and undoped materials for comparison to better understand the effect of doping on oxygen release (Supplementary Table 5$)^{40}$. O vacancy formation energy in NLNMFMB increases after B-doping. This indicates that the oxygen is difficult to escape from the lattice in B-doped material. Furthermore, charge density analysis shows that the NLNFMB possesses a stronger $\mathrm{B}-\mathrm{O}$ covalent bond with introducing extra electrons for the $\mathrm{O}$ atom (Fig. 2), in good agreement with the result of Bader charge analysis. The light-weight B-doping is therefore prone to strengthening the oxygen ligand framework from extra negative charge for $\mathrm{O}$ atom, thus favoring to reduce the loss of oxygen from the lattices and improve the structural stability.

Synthesis and structural analysis of materials. The NLNFM and NLNFMB samples were synthesized by a simple solid-state reaction. Inductively coupled plasma atomic emission spectroscopy (ICP-AES) was performed to confirm the stoichiometric ratio in NLNFMB. The atom ratio of Na:Li:Ni:Fe:Mn:B is 1.093:0.115:0.222:0.212:0.434:0.02 in NLNFMB, close to its chemical stoichiometric ratio. Scanning electron microscopy (SEM) image of NLNFMB shows the well-defined crystallites with ca. 13 $\mu \mathrm{m}$ in diameter (Supplementary Fig. 2a), which is larger than that of NLNFM (Supplementary Fig. 2b). All the diffraction peaks of two samples are indexed to a rhombohedral symmetry lattice with the space group $\mathrm{R} \overline{3} \mathrm{~m}$ (as shown by XRD patterns and corresponding Rietveld refinement in Fig. 3a, b), indicating an $\mathrm{O} 3$ phase material that sodium ions occupy octahedral sites and oxygen columns have an ABCABC-stacking mode (Supplementary Tables 6 and 7). The strong binding energy between $B$ and $O$ could contract the TM slabs, leading to the decreased lattice parameter $a$ after B-doping. The comparison of the two samples shows that the lattice parameters $c$ is increased after the B substitution, which is ascribed to the entry of extra coordinated B species with oxygen in transition metal layers. The increased electron density on oxygen has been confirmed from Bader charge calculation. The larger negative charges on oxygen, in turn, enlarge the interspacing of $\mathrm{TMO}_{2}$ slabs from 0.333 to $0.347 \mathrm{~nm}$ (Supplementary Table 8) due to the stronger electrostatic repulsion, resulting in the good $\mathrm{Na}^{+}$diffusion kinetics. The energy barriers for $\mathrm{Na}$-ion diffusion in layered oxide with and without B-doping were investigated in Supplementary Fig. 3. For the pristine NLNFM, the $\mathrm{Na}^{+}$diffusion energy barrier is calculated to be $0.45 \mathrm{eV}$ as hopping from one octahedral lattice site to its nearest vacant octahedral site by passing through a tetrahedral site. After B-doping, this diffusion barrier is lowered to $0.37 \mathrm{eV}$. This directly demonstrates that $\mathrm{B}$ interstitial dopant can decrease the diffusion barrier and hence facilitate the fast $\mathrm{Na}^{+}$diffusion. High-resolution transmission electron microscopy (HRTEM) observation shows that the NLNFMB samples are highly crystalline (Fig. 3c), with an interfringe distance of $0.54 \mathrm{~nm}$ corresponding to the (003) planes in rhombohedral symmetry. Energydispersive spectroscopy (EDS) mapping images demonstrate that $\mathrm{Na}, \mathrm{Ni}, \mathrm{Fe}, \mathrm{Mn}$, and $\mathrm{O}$ elements are uniformly distributed in the NLNFMB particle (Fig. 3d). To check the existence of $B$ in NLNFMB, X-ray photoelectron spectroscopy (XPS) was carried out. The signal peak of $192 \mathrm{eV}$ in B region of NLNFMB is clearly visible even $\mathrm{Ar}^{+}$etching 10 minutes (Supplementary Fig. 4a), demonstrating the B-doping into NLNFMB, whereas no signal peak of B $1 s$ is observed for NLNFM (Supplementary Fig. 4b). ToF-SIMS depth analysis shows that the $\mathrm{BO}_{2}-$ fragment without enriching on the surface of NLNFMB compound (Supplementary Fig. 5). All above, B is uniformly distributed throughout the particles.

Electrochemical performance. In order to verify the function of $B$ substitution, the electrochemical performances of NLNFM and NLNFMB cathodes were examined in 2032 coin cells using a sodium metal negative electrode between 2.0 and $4.3 \mathrm{~V}$. Figure $4 \mathrm{a}$, b shows the initial five galvanostatic charge/discharge (GCD) curves of NLNFM and NLNFMB cathodes at a specific current of 
a

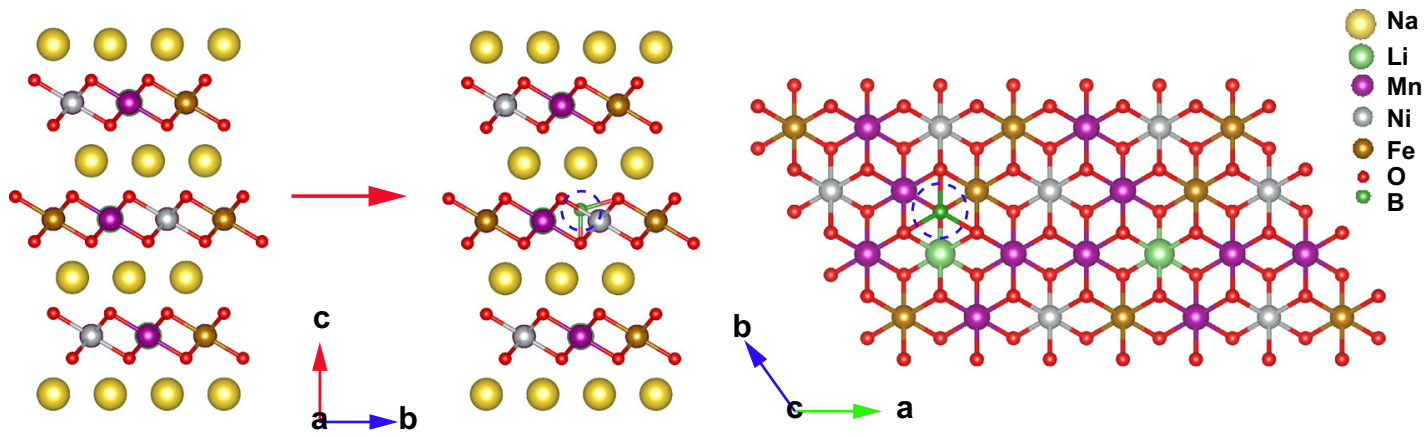

b
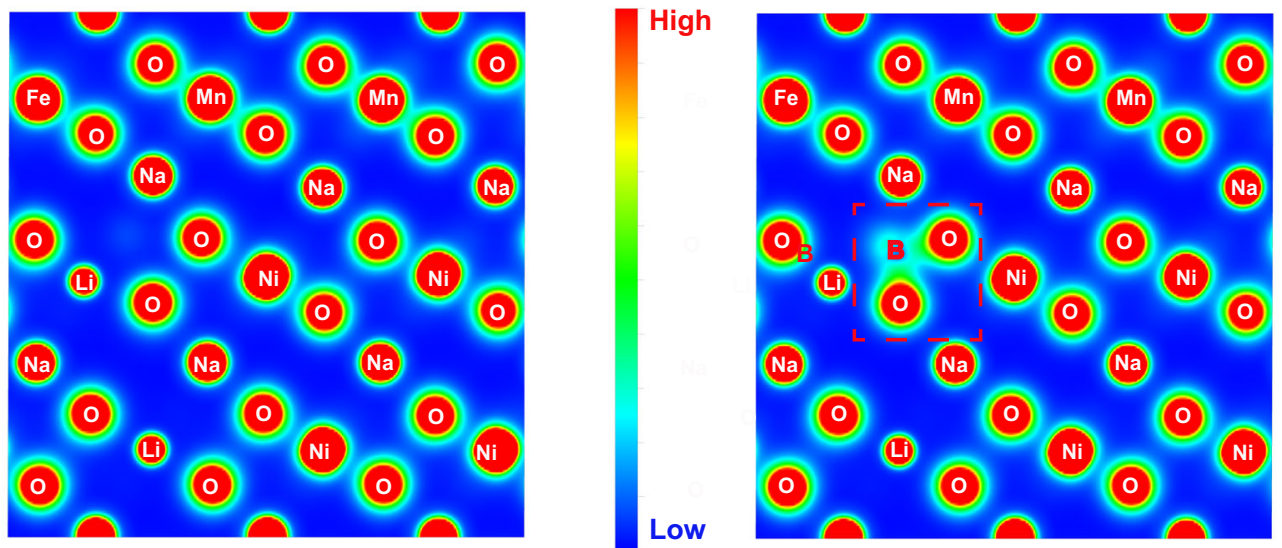

Fig. 2 Structure and charge density analysis. Schematic structures of NLNFM and NLNFMB (a). Contour maps of charge density on corresponding planes in NLNFM and NLNFMB (b).

$25 \mathrm{~mA} \mathrm{~g}^{-1}$. In the first cycle, the NLNFM cathode delivers a large

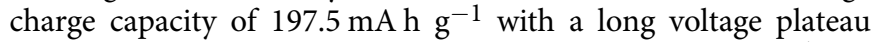
above $4.1 \mathrm{~V}$, which is equivalent to the removal of $\sim 0.78 \mathrm{Na}^{+}$per formula unit. The discharge capacity is $145.8 \mathrm{~mA} \mathrm{~h} \mathrm{~g}^{-1}$, giving rise to a low Coulombic efficiency of $73.8 \%$ in the first cycle. From the second cycle, the plateau above $4.1 \mathrm{~V}$ disappears, and the Coulombic efficiency increases to $94.5 \%$. In marked contrast to NLNFM, the NLNFMB cathode shows a charge capacity of $173.9 \mathrm{~mA} \mathrm{~h} \mathrm{~g}^{-1}$ (equivalent to the removal of $\sim 0.69 \mathrm{Na}^{+}$per formula unit) and a reversible discharge capacity of $160.5 \mathrm{~mA} \mathrm{~h} \mathrm{~g}^{-1}$ with a higher Coulombic efficiency of $92.3 \%$. In particular, the NLNFMB cathode exhibits a good match from the first to the fifth cycle, reflecting the good reversibility. Considering the discharge

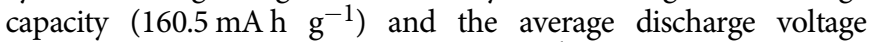
$(3.26 \mathrm{~V})$, a specific energy of $521 \mathrm{Wh} \mathrm{kg}^{-1}$ based on the mass of cathode material can be calculated for Na||NLNFMB coin cell. Note that the NLNFMB cathode exhibits the smooth sloping charge curve without a distinct plateau above $4.1 \mathrm{~V}$ in the first and subsequent cycles, which indicates the NLNFMB cathode possibly undergoes a distinct electrochemical reaction. The differential capacity analysis $\left(\mathrm{dQ} \mathrm{dV}^{-1}\right)$ plots of two cathodes were examined to further understand the electrochemical performances (Supplementary Fig. 6a, b). Two predominant redox peaks are observed for the NLNFM and NLNFMB cathodes: the peaks in low voltage region below $3 \mathrm{~V}$ are ascribed to $\mathrm{O} 3-\mathrm{P} 3$ phase transition, and the other peaks in high voltage region above $4.2 \mathrm{~V}$ are attributed to the P3-OP2 phase transition as discussed later. In addition, for NLNFM, an obvious oxidation peak at about $4.1 \mathrm{~V}$ in the first cycle shows up, without the corresponding reduction peak (Supplementary Fig. 6a). The absence indicates that the plateau about $4.1 \mathrm{~V}$ in charge/discharge curve is irreversible. In view that the electrolyte with $1 \mathrm{M} \mathrm{NaPF}_{6}$ in carbonate solvents is electrochemically stable within the operation voltage of the cathode ${ }^{41}$, the extra capacity contribution of the NLNFM cathode could come from the irreversible oxygen redox reaction, which is similar to the lithium-rich layered oxides ${ }^{42,43}$, and further confirmed by operando differential electrochemical mass spectrometry. Compared with the previously reported compound $\mathrm{Na}_{0.85} \mathrm{Li}_{0.1} \mathrm{Ni}_{0.18} \mathrm{Fe}_{0.18} \mathrm{Mn}_{0.54} \mathrm{O}_{2}$ which solely undergoes the cationic redox as being charged to $4.5 \mathrm{~V}$, our control material $\mathrm{NaLi}_{1 / 9} \mathrm{Ni}_{2 / 9} \mathrm{Fe}_{2 / 9} \mathrm{Mn}_{4 / 9} \mathrm{O}_{2}$ shows a complex $\mathrm{Na}$ storage electrochemistry that invites both cationic and anionic redox at a much lower voltage of $4.3 \mathrm{~V}$. This result indicates that even a subtle variation in chemical composition may have a prominent influence on the structural evolution and electrochemical $\mathrm{Na}$ storage mechanism of layered oxide cathodes. After doping with lightweight boron for NLNFMB, no oxidation peak at $4.1 \mathrm{~V}$ is observed in the first cycle, which is well consistent with the smooth sloping GCD curves for NLNFMB. The B-substituted NLNFMB thus delivers much better capacity retention $(76.3 \%)$ than that of B-free NLNFM (45.1\%) after 80 cycles at $25 \mathrm{~mA} \mathrm{~g}^{-1}$ (Fig. 4c). Furthermore, at a specific current of $500 \mathrm{mAg}^{-1}$ (Fig. 4d), the B-substituted NLNFMB cathode delivers an improved rate capability of $84.9 \mathrm{~mA} \mathrm{~h} \mathrm{~g}^{-1}$ compared with that of the unsubstituted NLNFM (35.6 $\mathrm{mA} \mathrm{h}^{-1}$ ), which is consistent with the results of lower energy barriers of $\mathrm{Na}^{+}$diffusion as calculated above. In particular, the comparison of long cycling performance at $1 \mathrm{C}$ $\left(250 \mathrm{~mA} \mathrm{~g}^{-1}\right)$ shows that the NLNFMB cathode maintains a much higher capacity retention of $82.8 \%$ after 200 cycles than that of the NLNFM cathode (66.2\%) (Fig. 4e). The NLNFMB electrodes exhibit stable Coulombic efficiency compared to NLNFM electrodes (Supplementary Fig. 7). The aforementioned results confirm that the doping of boron is beneficial to suppress irreversible oxygen redox reaction, guarantee good structural integrity, and endow the NLNFMB with the good electrochemical performance upon $\mathrm{Na}^{+}$ intercalation/deintercalation process. What's more, different content of boron doped into NLNFM were synthesized to check the 

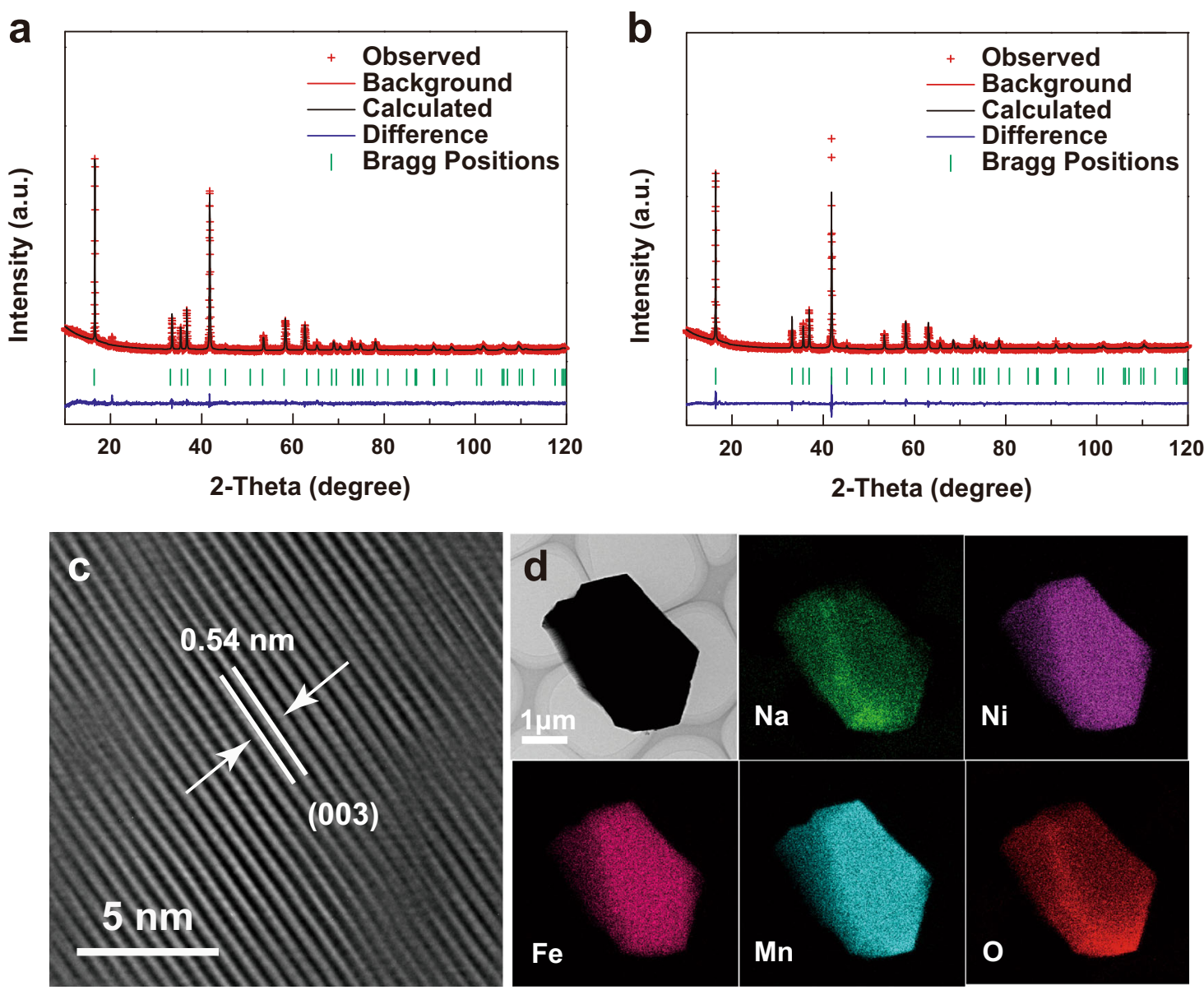

Fig. 3 Physicochemical measurements and analyses of the cathode active material powders. XRD and Rietveld refinement results of NLNFM (a) and $\operatorname{NLNFMB}(\mathbf{b})$, respectively. HRTEM images of (003) crystal planes (c) and EDS maps of NLNFMB (d).

optimal species. In Supplementary Fig. 8, XRD patterns show no impurities in $\mathrm{NaLi}_{1 / 9} \mathrm{Ni}_{2 / 9} \mathrm{Fe}_{2 / 9} \mathrm{Mn}_{4 / 9} \mathrm{~B}_{1 / 100} \mathrm{O}_{2}$ (NLNFMB0.01) while some impurities with the small peaks around $17^{\circ}$ appear in $\mathrm{NaLi}_{1 / 9} \mathrm{Ni}_{2 / 9} \mathrm{Fe}_{2 / 9} \mathrm{Mn}_{4 / 9} \mathrm{~B}_{1 / 25} \mathrm{O}_{2}$ (NLNFMB0.04). The related electrochemical performance was showed in Supplementary Fig. 9. The NLNFMB0.02 exhibits the highest discharge capacity and capacity retention of $82.8 \%$ compared with $68.3 \%$ for NLNFMB0.01 and $82.3 \%$ for NLNFMB0.04. Meanwhile, the corresponding Coulombic efficiency in Supplementary Fig. 10 shows the good reversibility of NLNFMB0.02. The electrochemical performance of hard carbon (HC) |NLNFMB full cells was further evaluated. The initial first GCD curve at 1C $\left(250 \mathrm{~mA} \mathrm{~g}^{-1}\right)$ shows that the full cell delivers a discharge capacity of $133.9 \mathrm{~mA} \mathrm{~h} \mathrm{~g}^{-1}$ based on the mass of cathode active material with the average voltage of $3.1 \mathrm{~V}$ (Fig. 5a), thus generating a specific energy of up to $224 \mathrm{Wh} \mathrm{kg}^{-1}$ based on the mass of NLNFMB and $\mathrm{HC}$ active material ${ }^{44,45}$. At a specific current of $1 \mathrm{C}\left(250 \mathrm{~mA} \mathrm{~g}^{-1}\right)$ (Fig. 5b), the full cell retains a high capacity of $80.1 \%$ after 100 cycles and a stable Coulombic efficiency (Supplementary Fig. 11). A comparison with other $\mathrm{Na-ion}$ full cells reported in the literature is disclosed in Supplementary Table $9^{46-48}$. Supplementary Fig. 12 shows a $71.28 \mathrm{mAh}$ singlecoated lab-scale Na-ion pouch cell comprising a pre-sodiated hard carbon-based anode and the pouch cell with B-doped cathode material could power light-emitting diode lamps as proof of concept.

Structural evolution. To further investigate the structural evolution of NLNFMB, in situ XRD patterns and corresponding intensity contour maps were recorded upon $\mathrm{Na}^{+}$intercalation/ deintercalation process of the first cycle. During the charging process (Fig. 6), the (003) and (006) peaks that are associated with the pristine $\mathrm{O} 3$ phase shift to a lower angle. The shift indicates the expansion of $c$ axis due to the increased electrostatic repulsion between adjacent oxygen layers. With charging to about $3.0 \mathrm{~V}$, an additional (003) XRD diffraction peak gradually appears at a lower angle. The appearance reflects the formation of the P3 phase, indeed consistent with the platform of the GCD curve in the voltage range between 2.9 and $3.0 \mathrm{~V}$. When the cell was continuously charged to $4.0 \mathrm{~V}$, the diffraction peaks associated with the $\mathrm{O} 3$ phase completely disappear, and the $\mathrm{P} 3$ phase is preserved. Upon the further extraction of $\mathrm{Na}$ ions, a new phase OP2 appears, accompanied by the reversible phase transformation of $\mathrm{P} 3$ phase, similar to the structural evolution of O3-type $\mathrm{NaFe}_{0.2} \mathrm{Mn}_{0.4} \mathrm{Ni}_{0.4} \mathrm{O}_{2}{ }^{49}$. Upon further charging to $4.3 \mathrm{~V}$, the (002) peak of OP2 phase shifts to higher angles, the contraction is well related to the oxidation of $\mathrm{O}^{2-}$ and the resultant smaller repulsion, as reported early for $\mathrm{LiCoO}_{2}$ or $\mathrm{Ni}$-rich $\mathrm{Li}$-based layered oxides ${ }^{50,51}$. During the subsequent discharge process, the NLNFMB electrode undergoes an exact opposite evolution of OP2-P3-O3, suggesting the highly reversible phase transformation during $\mathrm{Na}^{+}$intercalation/deintercalation process. By contrast, the B-free NLNFM electrode exhibits similar but different structural changes in Supplementary Fig. 13: during the charging process, the NLNFM electrode undergoes a same phase evolution of O3-P3-OP2, the $c$ parameter increases first and then decreases for both electrodes while $a$ parameter decreases first and then increases during the charging process. Note that 

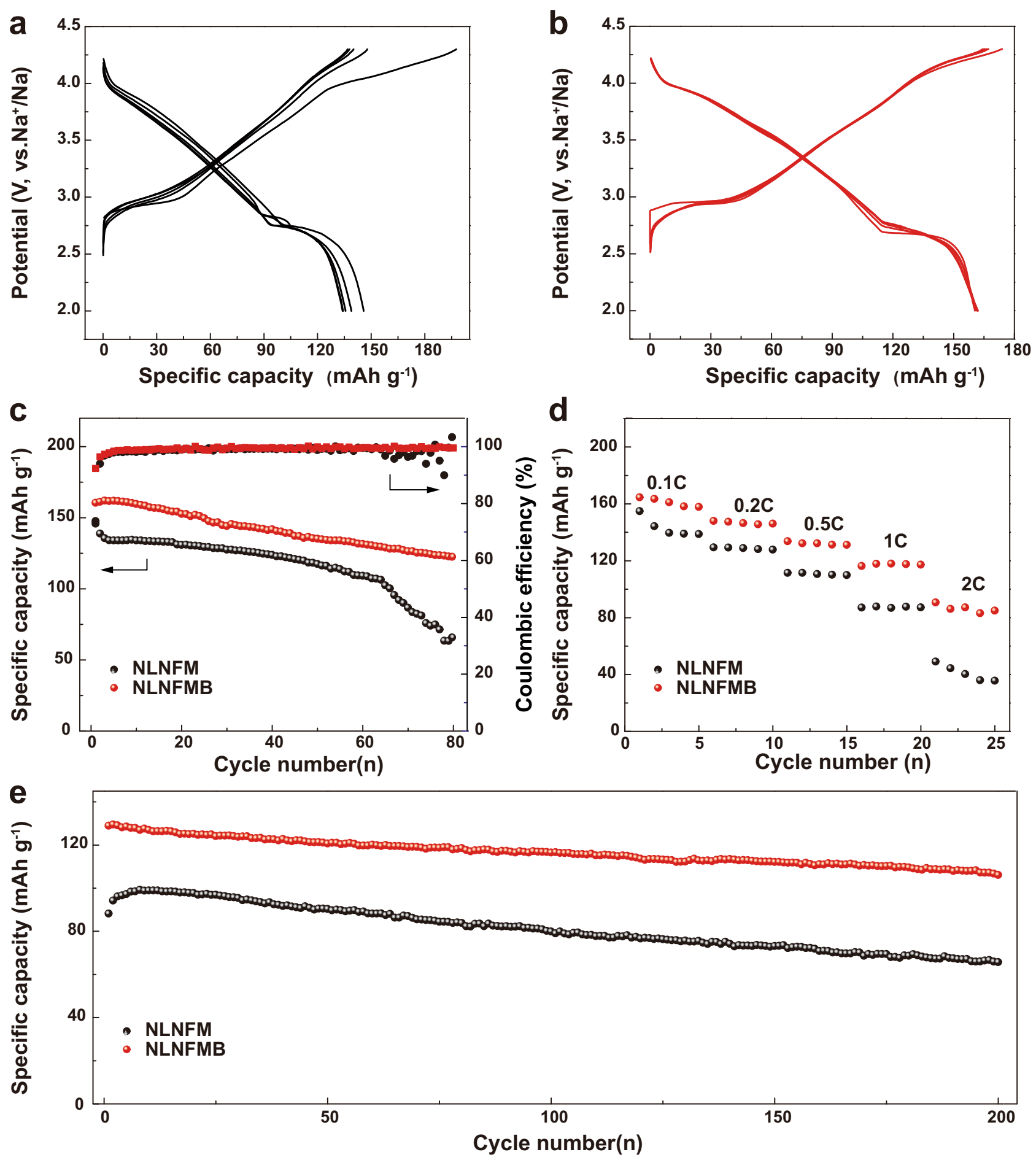

Fig. $4 \mathrm{Na}$-ion electrochemical energy storage performances in half-cell configuration at $25^{\circ} \mathrm{C}$. Galvanostatic charge/discharge voltage profiles of NLNFM (a) and NLNFMB (b) at $25 \mathrm{~mA} \mathrm{~g}^{-1}$ between 2.0 and $4.3 \mathrm{~V}$. Cycling performance at $25 \mathrm{~mA} \mathrm{~g}^{-1}$ (c), rate capability at various charge-discharge rates (d), and cycling performance at $250 \mathrm{~mA} \mathrm{~g}^{-1}\left(1 \mathrm{C}=250 \mathrm{~mA} \mathrm{~g}^{-1}\right)(\mathbf{e})$.

the lattice parameters change $\Delta c$ for NLNFMB is $4.8 \%$ slightly smaller than that of NLNFM (5.7\%), indicating the reduced lattice volume change and more stable structure of NLNFMB in Supplementary Fig. 14. A small amount of the P3 phase still remains at the end of discharging (Supplementary Fig. 13a, b), namely, the $\mathrm{O} 3$ and $\mathrm{P} 3$ phase co-exist after one charge/discharge process. After the completion of 200 cycles, the NLNFM structure is converted completely from the initial O3 phase to the $\mathrm{P} 3$ phase, whereas the NLNFMB sample still maintains the perfect
O3 phase (Supplementary Fig. 15a, b). We attribute the appearance of the P3 phase for NLNFM to the fact that the oxygen vacancies produced by oxygen loss result in the difficulty in re-insertion of $\mathrm{Na}^{+}$into lattices. Therefore, the B-doping reduces the variation of lattice parameters and facilitates the reversible $\mathrm{O} 3-\mathrm{P} 3-\mathrm{OP} 2$ phase transformation of NLNFMB, stabilizing the oxygen redox reaction and hence ensuring structural stability. 

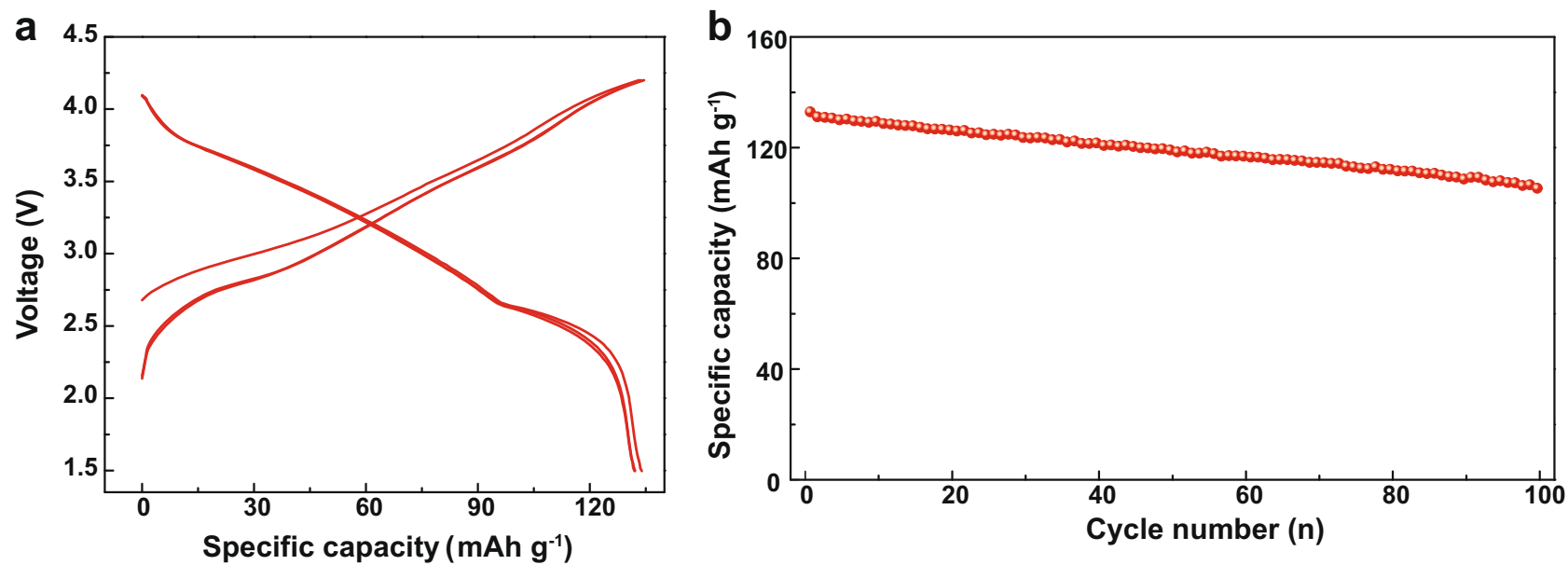

Fig. 5 Na-ion electrochemical energy storage performances in full-cell configuration. Galvanostatic charge/discharge voltage profiles between 1.5 and $4.2 \mathrm{~V}$ (a) and cycling performance at $250 \mathrm{~mA} \mathrm{~g}^{-1}$ for hard carbon||NLNFMB full cell (b).
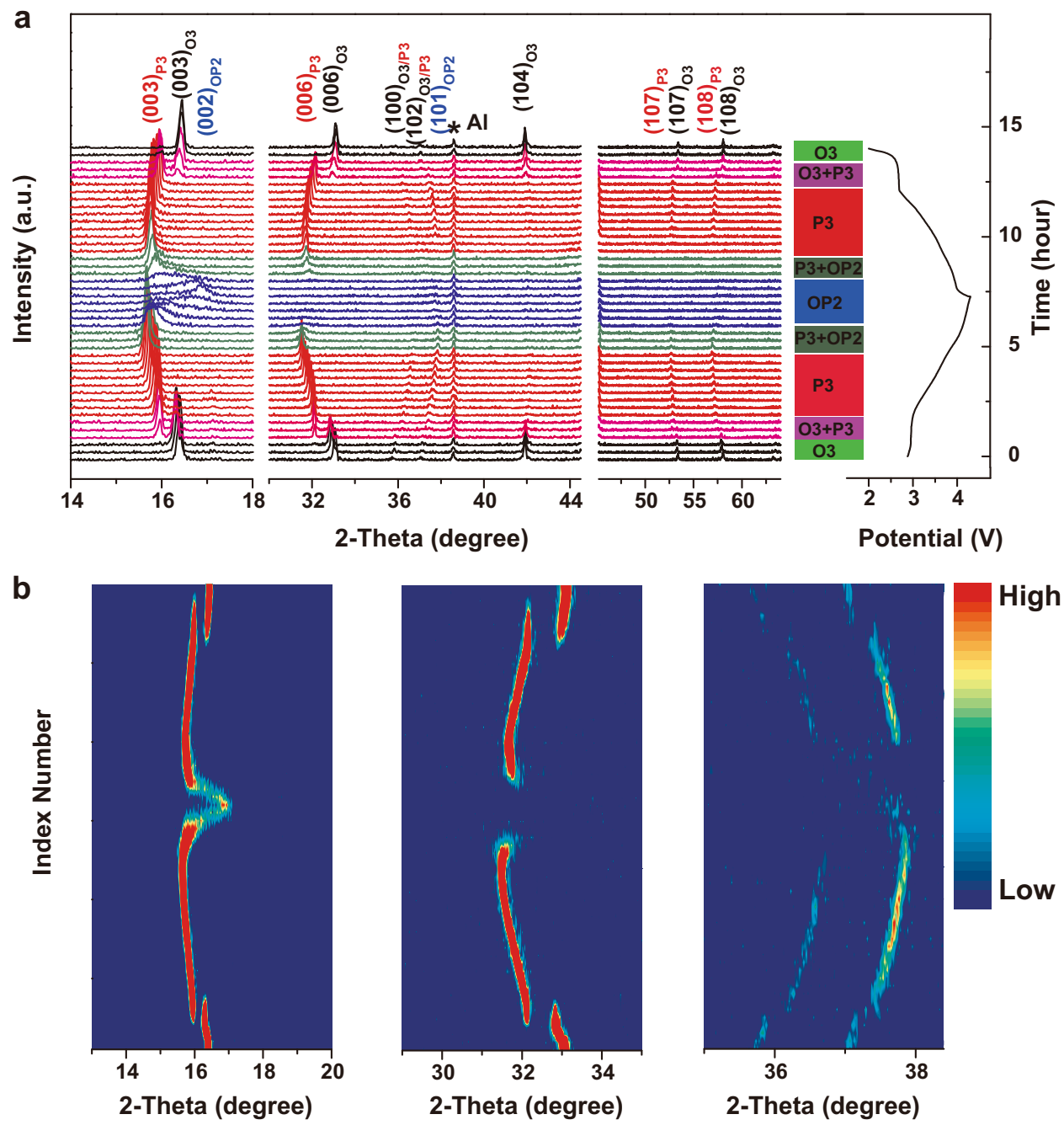

Fig. 6 Structural evolution of NLNFMB cathode material in half-cell configuration. In situ XRD patterns during the first charge/discharge of NLNFMB at a current rate of $0.1 \mathrm{C}\left(25 \mathrm{~mA} \mathrm{~g}^{-1}\right)$ between 2.0 and $4.3 \mathrm{~V}$ (a). Contour plot of main peak evolution (b). 

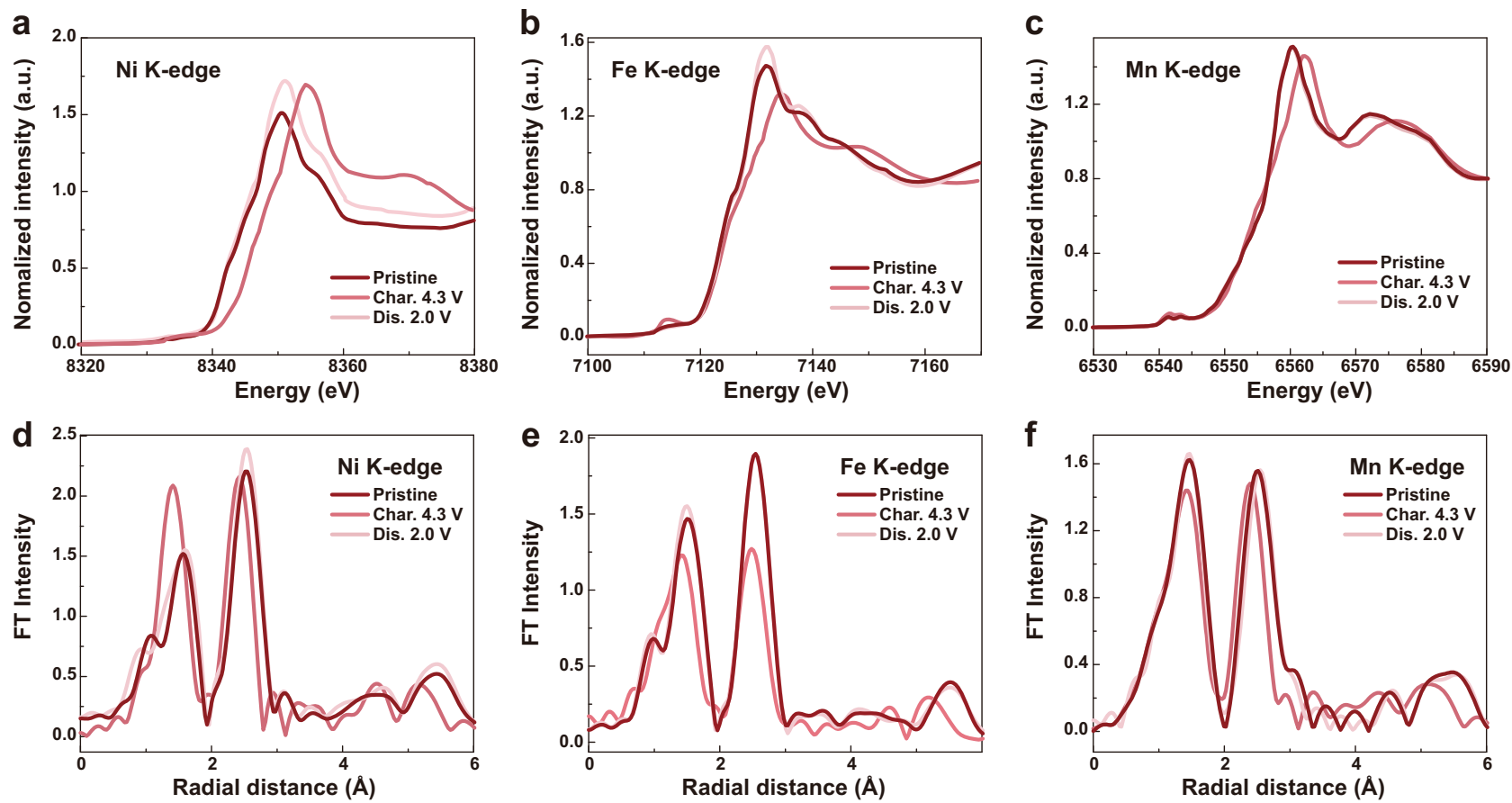

Fig. 7 Charge compensation mechanism upon at the first cycle in half-cell configuration. Ex situ XANES spectra at the $\mathrm{Ni}(\mathbf{a}), \mathrm{Fe}(\mathbf{b}), \mathrm{Mn}$ (c) $\mathrm{K}$-edge of NLNFMB at different charge/discharge states. Corresponding ex situ EXAFS spectra at the Ni (d), Fe (e), Mn (f) K-edge of NLNFMB electrodes at different charge/discharge states.

Charge compensation mechanism. Ex situ X-ray absorption spectroscopy (XAS) and ex situ XPS were used to probe the reaction mechanism during the charge/discharge process. X-ray absorption near edge structure (XANES) comparison between NLNFM and NLNFMB shows a slight shift of Fe and Mn absorption edge to lower energy after B substitution (Supplementary Fig. $16 \mathrm{a}-\mathrm{c}$ ). The shift indicates that $\mathrm{Fe}$ and $\mathrm{Mn}$ are reduced to lower valence, corroborating the successful B-doping into the structure. The lower valences of $\mathrm{Fe}$ and $\mathrm{Mn}$ are ascribed to the fact that $\mathrm{B}$ atom is surrounded by $\mathrm{Li}-\mathrm{Fe}-\mathrm{Mn}$, which has been discussed in the computational part. In addition, the lower valence of transition metal (TM) is responsible for the higher capacity of NLNFMB. Figure $7 \mathrm{a}-\mathrm{c}$ exhibits the normalized Ni, Fe, and Mn K-edge XANES spectra of NLNFMB sample at different charge/discharge states. The Ni K-edge XANES spectra show a significant shift towards higher energy $(\sim 3.4 \mathrm{eV})$ when charged to $4.3 \mathrm{~V}$, which is larger than $\mathrm{Ni}^{2+}$ to $\mathrm{Ni}^{3+}$ redox change $(\sim 2 \mathrm{eV})$ but smaller than $\mathrm{Ni}^{2+}$ to $\mathrm{Ni}^{4+}$ redox change $(\sim 4 \mathrm{eV})$, indicating the redox reaction from $\mathrm{Ni}^{2+}$ to $\mathrm{Ni}^{3+}$ and partly oxidized to $\mathrm{Ni}^{4+15,52}$. When discharged to $2.0 \mathrm{~V}$, the Ni K-edge XANES spectra recover to the initial position, suggesting that the Ni redox is electrochemically reversible. Similarly, the Fe K-edge XANES spectra shows slight but obvious shift towards higher energy when charged to $4.3 \mathrm{~V}$, which demonstrates that Fe is oxidized to a higher valence and also return to the pristine position upon further discharge. Moreover, the Mn K-edge XANES spectra show a slight shift when the NLNFMB was charged to $4.3 \mathrm{~V}$, and recover to the initial as discharged to $2.0 \mathrm{~V}$. However, only few $\mathrm{Mn}$ involves the charge compensation, albeit the local environment of Mn center could sensitively influence the shape of Mn $\mathrm{K}$-edge spectra ${ }^{53}$. This is because that the $\mathrm{B}$ substitution has a weaker influence on Mn than on Fe (Supplementary Fig. 16). In the case of NLNFM, the Ni and Mn K-edge XANES spectra show the evolution similar to that of NLNFMB (Supplementary Fig. 17); while the Fe K-edge XANES spectra show an inappreciable shift towards the higher energy as charged to $4.3 \mathrm{~V}$. The result reflects that few $\mathrm{Fe}$ involves the charge compensation during the charging process. Furthermore, the energy shift of Fe K-edge in NLNFMB is about $\sim 0.9 \mathrm{eV}$, larger than that of NLNFM $(0.5 \mathrm{eV})$, suggesting more Fe participate in charge compensation for NLNFMB than for NLNFM (Supplementary Fig. 18). And ex situ XPS was carried on to investigate the Fe $2 p$ peaks in layered oxide electrode charged to $4.3 \mathrm{~V}$ (Supplementary Fig. 19). The peak area at $715.3 \mathrm{eV}$ of NLNFMB is larger than that of NLNFM, indicating more $\mathrm{Fe}^{3+}$ were oxidized to $\mathrm{Fe}^{4+}$. Therefore, more Fe participates in charge compensation for NLNFMB than for NLNFM, thus favoring the high reversible capacity of NLNFMB.

Further comparison of extended X-ray absorption fine structure (EXAFS) spectra at $\mathrm{Ni}, \mathrm{Fe}$, and $\mathrm{Mn} \mathrm{K}$-edge are made between NLNFMB and NLNFM to gain the local coordination information ${ }^{54}$. The significant changes of EXAFS peak intensity in discharge cutoff state and initial state for NLNFM indicate the obvious structural changes (Supplementary Fig. 17). Figure $7 \mathrm{~d}-\mathrm{f}$ shows that the intensity of both TM-TM and TM-O coordination shells of NLNFMB sample returns to the initial state upon discharging to $2.0 \mathrm{~V}$. However, this is not the case for the B-free NLNFM sample after the completion of discharging to $2.0 \mathrm{~V}$. All the aforementioned results suggest that the NLNFMB possesses the good structural stability during the charge/discharge process, which is consistent with the reversible phase transition of NLNFMB observed by in situ XRD.

XPS technique was used to probe the oxygen redox reaction species (Supplementary Figure 20). A pronounced peak at $530.9 \mathrm{eV}$ is visible for the NLNFMB and NLNFM when charged to $4.3 \mathrm{~V}$, which is ascribed to the oxidation of $\mathrm{O}^{2-}$ with the formation of peroxo-related species $\left(\mathrm{O}_{2}{ }^{n-}\right)^{4}$. The presence informs that the two samples both undergo oxygen redox reaction. Comparison of O1s spectrum between the NLNFM and NLNFMB samples shows the larger area and higher intensity of $\mathrm{O} 1 \mathrm{~s}$ spectrum around the higher binding energy region of NLNFM. This indicates the high-amount decomposition species 

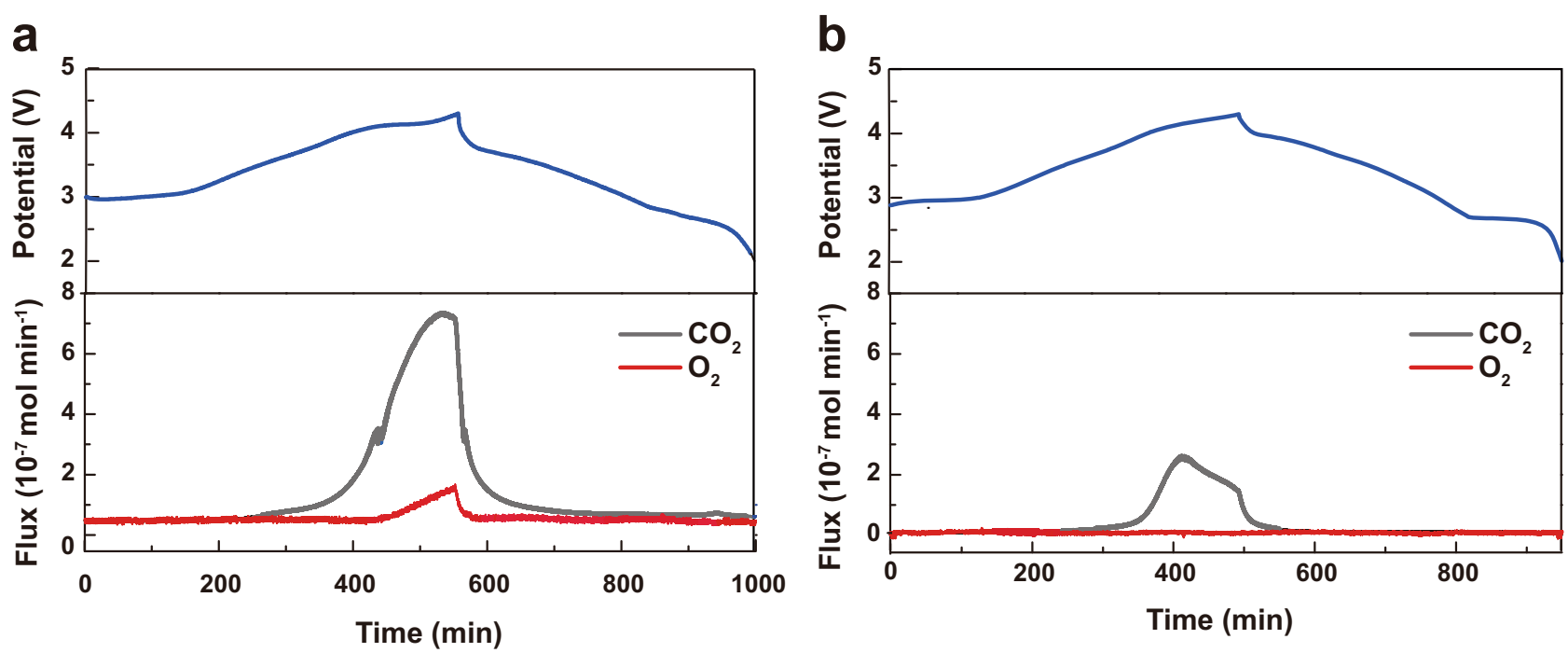

Fig. 8 Gas loss of NLNFM and NLNFMB during (de)sodiation. DEMS data collected during the first cycle of NLNFM (a) and NLNFMB (b).

of electrolyte, thus forming the thick and resistive CEI and incurring the poor rate capability. The peak at $530.9 \mathrm{eV}$ is invisible when discharged to $2 \mathrm{~V}$, demonstrates the reduction of released oxygen species, and peroxo-related species $\left(\mathrm{O}_{2}{ }^{n-}\right)$ at $530.9 \mathrm{eV}$ appears again at the 2 nd cycle, demonstrating the reversible oxygen redox in NLNFMB (Supplementary Fig. 21).

To further check the oxygen release from lattice due to the irreversible oxygen redox reaction, differential electrochemical mass spectrometry (DEMS) was used during $\mathrm{Na}^{+}$intercalation/ deintercalation process. The evolution of both $\mathrm{O}_{2}$ and $\mathrm{CO}_{2}$ is clearly detected during the charging of NLNFM (Fig. 8a, b). The detected $\mathrm{CO}_{2}$ gas is associated with the decomposition of a small amount of $\mathrm{Na}_{2} \mathrm{CO}_{3}$ and electrolyte oxidation when charged to the high voltage range from $3.5 \mathrm{~V}$ to $4.3 \mathrm{~V}^{10}$, and the formed $\mathrm{O}_{2}$ gas during charging to high voltage region is well related to the irreversibility of oxygen redox reaction resulting from oxygen loss from the lattice, responsible for the anomalously large capacity at the first charge of the initial GCD curve. In addition, the continuous $\mathrm{O}_{2}$ release was detected in the subsequent cycles upon charging the NLNFM sample (Supplementary Fig. 22). This pronounced oxygen release from lattice upon repeated cycles is also responsible for the above-mentioned capacity fading and the structural instability of the NLNFM during the cycling. Eventually, the NLNFM undergoes the irreversible structural transformation from the co-existing $\mathrm{O} 3 / \mathrm{P} 3$ phases after one charge/discharge procedure (as evidenced by in situ XRD patterns), to the only P3 phase after the completion of 200 cycles (as shown by ex situ XRD patterns in Supplementary Fig. 15a). In marked contrast to NLNFM, the NLNFMB exhibits a completely different picture for the DEMS curve that no oxygen release evolved but instead only a small quantity of $\mathrm{CO}_{2}$ detected (Fig. 8b). The result strongly suggests that the incorporation of boron ions indeed suppresses the irreversible oxygen redox reaction, thus endowing the smooth GCD curve above $4.1 \mathrm{~V}$ and improving the structural stability. We estimated the capacity contribution provided by cationic redox and anionic redox in the first cycle based on $\mathrm{Ni}$ and $\mathrm{Fe} \mathrm{K}$-edge XANES spectra (Supplementary Fig. 23). We can see that the NLNFM delivers a low capacity from cationic redox $\left(120 \mathrm{mAh} \mathrm{g}^{-1}\right)$ and a larger capacity from anionic redox $\left(77 \mathrm{mAh} \mathrm{g}^{-1}\right)$, whereas the B-doped NLNFM shows a higher capacity from cationic redox (130 $\left.\mathrm{mAh}^{-1}\right)$ and slightly lower capacity from anionic

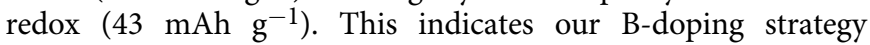
effectively suppresses the irreversible oxygen loss and facilitates more cationic redox concurrently.

\section{Discussion}

In summary, we have demonstrated an improvement strategy of doping light-weight boron ions into the NLNFM lattices to effectively stabilize the reversible oxygen redox at charging high voltage region. Each $\mathrm{B}-\mathrm{O}$ bond can accommodate extra negative valence change to $\mathrm{O}$ atom due to the strong covalent bond of boron with oxygen, which is conducive to alleviate the oxidation of $\mathrm{O}$ for charge compensation and successfully suppresses the irreversible oxygen redox as proved by DEMS. In particular, the boron doping promotes the reversible phase transition evidenced by in situ XRD. Therefore, B substitution facilitates the high reversibility of oxygen redox reaction and retains good structure stability, thus boosting the excellent cycling stability. In the meantime, B-doping could enhance Na-ion diffusion kinetics, resulting in a good rate performance. Another bonus brought by B-doping is a more cationic redox reaction. As a result, the NLNFMB electrodes show a reversible capacity of $160.5 \mathrm{mAh} \mathrm{g}^{-1}$ at $25 \mathrm{mAg}^{-1}$ and a reversible discharge of $120 \mathrm{mAh} \mathrm{g}^{-1}$ at $250 \mathrm{~mA} \mathrm{~g}^{-1}$ with excellent cycling stability (82.8\% after 200 cycles). This light-weight B substitution provides a feasible method to suppress the detrimentally irreversible oxygen release with a positive capacity contribution. The alternative light-weight elements $(\mathrm{P}, \mathrm{Si})$ with strong oxygen binding are expected to stabilize the oxygen redox and realize the highcapacity cathodes for NIBs and LIBs as well.

\section{Methods}

Materials preparation. The $\mathrm{NaLi}_{1 / 9} \mathrm{Ni}_{2 / 9} \mathrm{Fe}_{2 / 9} \mathrm{Mn}_{4 / 9} \mathrm{O}_{2}$ (NLNFM) and $\mathrm{NaLi}_{1 / 9} \mathrm{Ni}_{2 / 9} \mathrm{Fe}_{2 / 9} \mathrm{Mn}_{4 / 9} \mathrm{~B}_{1 / 50} \mathrm{O}_{2}$ (NLNFMB) compounds were synthesized by simple solid-state reactions. The stoichiometric mixtures of $\mathrm{Na}_{2} \mathrm{CO}_{3}$ (99.5\%; Alfa Aesar), $\mathrm{Li}_{2} \mathrm{CO}_{3}$ (99.5\%; Alfa Aesar), $\mathrm{Fe}_{2} \mathrm{O}_{3}$ (99.9\%; Alfa Aesar), $\mathrm{Mn}_{2} \mathrm{O}_{3}$ (98\%; Alfa Aesar), and $\mathrm{B}_{2} \mathrm{O}_{3}$ (99.9\%, Alfa Aesar) were ground and then calcined at $950^{\circ} \mathrm{C}$ for $15 \mathrm{~h}$, after cooling to room temperature, and transferred to an argonfilled glove box immediately.

Materials characterization. X-ray powder diffraction was collected in a Bruker D8 Advance diffractometer with $\mathrm{Cu}$ Ka radiation $(\lambda=1.5418 \AA)$. The TOPAS software s was utilized to analyze the crystal structure based on the Rietveld refinement method. A specially designed Swagelok cell was equipped with an aluminum window for X-ray penetration for in situ XRD experiment. The specific ratios of the samples were measured by inductively coupled plasma atomic emission spectrometry (ICP-AES; Thermo Icap 6300). The sample was dissolved by aqua regia and measured with the diluted solvent. The morphologies and microstructures were characterized by using scanning electron microscopy (SEM; JEOL JSM-6701F). The HRTEM image and EDS maps were examined by TEM (JEM; 2100F). XPS measurements were carried out with an AXIS Supra using an $\mathrm{Al} \mathrm{Ka}$ achromatic X-ray source. XAS measurements were 
carried out at beamline BL14W1 of the Shanghai Synchrotron Radiation Facility (SSRF), China, operating with a Si (111) double-crystal monochromator. The OmniStar GSD 320 instrument with QMA 200M analyzer and C-SEM/Faraday detector was used to collect the differential electrochemical mass spectrometry (DEMS) spectra. The SIMS analysis was performed with a ToF-SIMS 5 instrument (ION-ToF GmbH, Münster, Germany) equipped with a $30 \mathrm{keV} \mathrm{Bi}^{3+}$ primary ion gun and a $2 \mathrm{keV} \mathrm{Cs}^{+}$sputter gun. An electron flood gun was used for charge neutralization.

Electrochemical characterizations. The electrochemical performance of NLNFM and NLNFMB compounds were completed in CR2032 coin-type cells and collected on an Arbin BT2000 system. The working electrode consists of 80 wt.\% active materials, $10 \mathrm{wt} . \%$ conductive carbon (super P), and $10 \mathrm{wt} \%$ polyvinylidene fluoride (PVdF) binder. The prepared slurry was cast onto an $\mathrm{Al}$ foil and dried at $80^{\circ} \mathrm{C}$ overnight under a vacuum. The areal mass loading of active material on the cathode was $\sim 3.5 \mathrm{mg} \mathrm{cm}^{-2}$. Na half cells based on CR2032 coin-cell configuration were assembled in an argon-filled glove box $\left(\mathrm{H}_{2} \mathrm{O} \leq 0.1 \mathrm{ppm} ; \mathrm{O}_{2} \leq 0.1 \mathrm{ppm}\right)$ by pairing the cathode with a Na-metal disc (99.8\%; Alfa Aesar) as the anode. Both electrodes had a diameter of $10 \mathrm{~mm}$, and were separated by a Whatman glass fiber (diameter: $20 \mathrm{~mm}$ ), on which $180 \mu \mathrm{L}$ of electrolyte was added to ensure complete wetting of both electrodes. The electrolyte consisted of $1 \mathrm{M} \mathrm{NaPF}_{6}$ in ethylene carbonate (EC) and diethyl carbonate (DEC) (1:1 in volume; with the addition of 5 vol.\% fluoroethylene carbonate, FEC; $\left.\mathrm{H}_{2} \mathrm{O} \leq 20 \mathrm{ppm}\right)$. The charge/discharge data were collected between 2.0 and $4.3 \mathrm{~V}$ at various rates under $25^{\circ} \mathrm{C}$. For the full cells, the active materials of the anode are hard carbon (HC) and the HC electrode consists of 80 wt.\% active materials, $10 \mathrm{wt} . \%$ conductive carbon (super P), and $10 \mathrm{wt} . \%$ PVdF binder. We assembled two kinds of full cells, e.g., 2032 coin cell, and pouch cell with a single-layer configuration. The electrodes are single side coated. The HC anode was pre-sodiated with $\mathrm{Na}$ metal and subsequently paired with the NLNFMB cathode at a N/P ratio of 1.2. Galvanostatic charge/discharge measurements of coin cells were performed under $25^{\circ} \mathrm{C}$ between 1.5 and $4.2 \mathrm{~V}$ at $1 \mathrm{C}$ $\left(1 \mathrm{C}=250 \mathrm{mAh} \mathrm{g}^{-1}\right.$ based on the cathode specific capacity in the half-cell test). In the pouch cell, the area of the cathode is $71.28 \mathrm{~cm}^{2}$ with designed areal capacity of $1 \mathrm{mAh} \mathrm{cm}-2$ and the areal mass loading of the $\mathrm{HC}$ anode is $4.2 \mathrm{mg} \mathrm{cm}^{-2}$. The overall capacity of the pouch cell in Fig. $5 \mathrm{~b}$ is $71.28 \mathrm{mAh}$. The pouch cell was used to power the light-emitting diodes with the logo of "ICCAS" at full charge state.

Specific energy calculation. According to the formula, $E_{\mathrm{C}}=C_{\mathrm{C}} * V_{\mathrm{C}}$, where $E_{\mathrm{C}}$ denotes the specific energy, $C_{C}$ denotes the gravimetric-specific capacity of the cathode material and $\mathrm{V}_{\mathrm{C}}$ denotes the average voltage of the half cell (which approximates the average cathode potential vs. $\mathrm{Na}^{+} / \mathrm{Na}$ ). In this way, a specific energy of $521 \mathrm{Wh} \mathrm{kg}^{-1}$ based on the mass of cathode material can be calculated for Nal|NLNFMB coin cell $\left(C_{C}=160.5 \mathrm{mAh} \mathrm{g}^{-1} ; \mathrm{V}_{\mathrm{C}}=3.25 \mathrm{~V}\right)$. The specific energy of the full cell was calculated based on the cathode specific capacity $\left(133.9 \mathrm{mAh} \mathrm{g}^{-1}\right)$, the average voltage of the full cell $\left(V_{\mathrm{C}}=3.1 \mathrm{~V}\right)$, and a N/P ratio of 1.2 adopted for the cell manufacture, which gave a value of $224 \mathrm{Wh} \mathrm{kg}^{-1}$.

Computational details. All first-principle calculations were performed in spinpolarized mode with density functional theory (DFT) by the projector-augmented wave (PAW) method implemented in the VASP package ${ }^{55}$. The generalized gradient approximation as developed by Perdew, Burke, and Ernzerhof $(\mathrm{PBE})^{56}$ is employed. Hubbard $U$ potential correction was applied to take into account the self-interactions of on-site d-orbital in $\mathrm{Mn}(3.9 \mathrm{eV}), \mathrm{Fe}(4.0 \mathrm{eV}), \mathrm{Ni}(6.0 \mathrm{eV})$ atoms ${ }^{57}$. The kinetic energy cutoff $400 \mathrm{eV}$ and a $\Gamma$-centered $2 \times 2 \times 1 \mathrm{k}$-mesh in the Brillouin zone have been utilized for the convergence of total energy with a criterion of $1 \times 10^{-4} \mathrm{eV}$ per atom.

The $\mathrm{O}$ vacancy formation energy for the $\mathrm{B}$-doped and undoped materials was calculated based on the following formula: $E_{\mathrm{f}, \mathrm{Ovac}}=E_{\mathrm{ovac}}-E_{\text {pristine }}+1 / 2 E_{2}$, where $E_{\mathrm{f}, \mathrm{Ovac}}$ is the formation energy of $\mathrm{O}$ vacancy, $E_{\mathrm{Ovac}}$ and $E_{\text {pristine }}$ are the energy of lattice structures with and without the $\mathrm{O}$ vacancy, and $\mathrm{Eo}_{2}$ is the calculated energy for $\mathrm{O}_{2}$ molecule. The capacity change ratio was calculated based on the formula: $\frac{\text { Capacity after doping-capacity before doping }}{\text { Capacity before doping }}$

\section{Data availability}

The data that supporting the findings of this study are available from the corresponding author on reasonable request.

Received: 13 November 2020; Accepted: 12 August 2021; Published online: 06 September 2021

\section{References}

1. Yabuuchi, N., Kubota, K., Dahbi, M. \& Komaba, S. Research development on sodium-ion batteries. Chem. Rev. 114, 11636-11682 (2014).
2. Chayambuka, K., Mulder, G., Danilov, D. L. \& Notten, P. H. L. Sodium-ion battery materials and electrochemical properties reviewed. Adv. Energy Mater. 8, 1800079 (2018)

3. Luo, K. et al. Charge-compensation in 3d-transition-metal-oxide intercalation cathodes through the generation of localized electron holes on oxygen. Nat. Chem. 8, 684-691 (2016).

4. McCalla, E. et al. Visualization of O-O peroxo-like dimers in high-capacity layered oxides for Li-ion batteries. Science 350, 1516-1521 (2015).

5. Seo, D.-H. et al. The structural and chemical origin of the oxygen redox activity in layered and cation-disordered Li-excess cathode materials. Nat. Chem. 8, 692-697 (2016).

6. Zhao, E. et al. Local structure adaptability through multi cations for oxygen redox accommodation in Li-Rich layered oxides. Energy Storage Mater. 24, 384-393 (2020).

7. Assat, G. \& Tarascon, J.-M. Fundamental understanding and practical challenges of anionic redox activity in Li-ion batteries. Nat. Energy 3, 373-386 (2018).

8. Wen, W., Kumarasamy, B., Mukerjee, S., Auinat, M. \& Ein-Eli, Y. Origin of 5 $\mathrm{V}$ electrochemical activity observed in non-redox reactive divalent cation doped $\mathrm{LiM}_{0.5-\mathrm{x}} \mathrm{Mn}_{1.5+\mathrm{x}} \mathrm{O}_{4}(0 \leq \mathrm{x} \leq 0.5)$ cathode materials. J. Electrochem. Soc. 152, A1902-A1911 (2005).

9. Ben Yahia, M., Vergnet, J., Saubanere, M. \& Doublet, M. L. Unified picture of anionic redox in Li/Na-ion batteries. Nat. Mater. 18, 496-502 (2019).

10. Maitra, U. et al. Oxygen redox chemistry without excess alkali-metal ions in $\mathrm{Na}_{2 / 3}\left[\mathrm{Mg}_{0.28} \mathrm{Mn}_{0.72}\right] \mathrm{O}_{2}$. Nat. Chem. 10, 288-295 (2018).

11. Pearce, P. E. et al. beta- $\mathrm{Na}_{1.7} \mathrm{IrO}_{3}$ : a tridimensional Na-ion insertion material with a redox active oxygen network. Chem. Mater. 30, 3285-3293 (2018).

12. Tamaru, M., Wang, X., Okubo, M. \& Yamada, A. Layered $\mathrm{Na}_{2} \mathrm{RuO}_{3}$ as a cathode material for Na-ion batteries. Electrochem. Commun. 33, 23-26 (2013).

13. Zhang, K. et al. Manganese based layered oxides with modulated electronic and thermodynamic properties for sodium ion batteries. Nat. Commun. 10, 5203 (2019).

14. Zhang, X. et al. Manganese-based Na-rich materials boost anionic redox in high-performance layered cathodes for sodium-ion batteries. Adv. Mater. 31, 1807770 (2019).

15. Li, Q. et al. Both cationic and anionic co-(de)intercalation into a metal-oxide material. Joule 2, 1134-1145 (2018).

16. Qiao, Y. et al. Reversible anionic redox activity in $\mathrm{Na}_{3} \mathrm{RuO}_{4}$ cathodes: a prototype Na-rich layered oxide. Energy Environ. Sci. 11, 299-305 (2018).

17. Jo, J. H. et al. Sodium-ion batteries: building effective layered cathode materials with long-term cycling by modifying the surface via sodium phosphate. Adv. Funct. Mater. 28, 1705968 (2018).

18. Ma, C. et al. Exploring oxygen activity in the high energy P2-type $\mathrm{Na}_{0.78} \mathrm{Ni}_{0.23} \mathrm{Mn}_{0.69} \mathrm{O}_{2}$ cathode material for Na-ion batteries. J. Am. Chem. Soc 139, 4835-4845 (2017).

19. Kim, J. et al. Controllable solid electrolyte interphase in nickel-rich cathodes by an electrochemical rearrangement for stable lithium-ion batteries. $A d v$. Mater. 30, 1704309 (2018).

20. Jung, S. C., Kim, H.-J., Choi, J. W. \& Han, Y.-K. Sodium ion diffusion in $\mathrm{Al}_{2} \mathrm{O}_{3}$ : a distinct perspective compared with lithium ion diffusion. Nano Lett. 14, 6559-6563 (2014)

21. Hwang, J.-Y., Yu, T.-Y. \& Sun, Y.-K. Simultaneous $\mathrm{MgO}$ coating and $\mathrm{Mg}$ doping of $\mathrm{Na}\left[\mathrm{Ni}_{0.5} \mathrm{Mn}_{0.5}\right] \mathrm{O}_{2}$ cathode: facile and customizable approach to high-voltage sodium-ion batteries. J. Mater. Chem. A 6, 16854-16862 (2018),

22. Jo, C.-H. et al. Bioinspired surface layer for the cathode material of highenergy-density sodium-ion batteries. Adv. Energy Mater. 8, 1702942 (2018).

23. Cao, X. et al. Restraining oxygen loss and suppressing structural distortion in a newly Ti-substituted layered oxide $\mathrm{P} 2-\mathrm{Na}_{0.66} \mathrm{Li}_{0.22} \mathrm{Ti}_{0.15} \mathrm{Mn}_{0.63} \mathrm{O}_{2}$. ACS Energy Lett. 4, 2409-2417 (2019).

24. Ma, Q. et al. Improving rate capability and decelerating voltage decay of Lirich layered oxide cathodes via selenium doping to stabilize oxygen. J. Power Sources 331, 112-121 (2016).

25. Liu, S. et al. Surface doping to enhance structural integrity and performance of Li-rich layered oxide. Adv. Energy Mater. 8, 1802105 (2018).

26. Xiao, P., Deng, Z. Q., Manthiram, A. \& Henkelman, G. Calculations of oxygen stability in lithium-rich layered cathodes. J. Phys. Chem. C 116, 23201-23204 (2012).

27. Lei, Y. et al. Surface modification of Li-rich Mn-based layered oxide cathodes challenges, materials, methods, and characterization. Adv. Energy Mater. 10, 2002506 (2020).

28. Sharifi-Asl, S., Lu, J., Amine, K. \& Shahbazian-Yassar, R. Oxygen release degradation in Li-ion battery cathode materials: mechanisms and mitigating approaches. Adv. Energy Mater. 9, 1900551 (2019).

29. Hu, S. et al. Li-rich layered oxides and their practical challenges: recent progress and perspectives. Electrochem. Energ. Rev. 2, 277-311 (2019).

30. Sun, L. Q. et al. Insight into Ca-substitution effects on O3-type $\mathrm{NaNi}_{1 / 3} \mathrm{Fe}_{1 /}$ ${ }_{3} \mathrm{Mn}_{1 / 3} \mathrm{O}_{2}$ cathode materials for sodium-ion batteries application. Small 14, 1704523 (2018) 
31. Sun, X. et al. $\mathrm{Na}\left[\mathrm{Ni}_{0.4} \mathrm{Fe}_{0.2} \mathrm{Mn}_{0.4-\mathrm{x}} \mathrm{Ti}_{\mathrm{X}}\right] \mathrm{O}_{2}$ : a cathode of high capacity and superior cyclability for Na-ion batteries. J. Mater. Chem. A 2, 17268-17271 (2014).

32. Wang, P.-F. et al. Suppressing the P2-O2 phase transition of $\mathrm{Na}_{0.67} \mathrm{Mn}_{0.67} \mathrm{Ni}_{0.33} \mathrm{O}_{2}$ by magnesium substitution for improved sodium-ion batteries. Angew. Chem. Int. Ed. 55, 7445-7449 (2016).

33. $\mathrm{Li}, \mathrm{C}$. et al. Unraveling the critical role of Ti substitution in $\mathrm{P} 2-\mathrm{Na}_{\mathrm{x}} \mathrm{Li}_{\mathrm{y}} \mathrm{Mn}_{1-\mathrm{y}} \mathrm{O}_{2}$ cathodes for highly reversible oxygen redox chemistry. Chem. Mater. 32, 1054-1063 (2020).

34. You, Y. et al. Insights into the improved high-voltage performance of Liincorporated layered oxide cathodes for sodium-ion batteries. Chem 4, 2124 (2018).

35. Vaalma, C., Buchholz, D. \& Passerini, S. Beneficial effect of boron in layered sodium-ion cathode materials-the example of $\mathrm{Na}_{2 / 3} \mathrm{~B}_{0.11} \mathrm{Mn}_{0.89} \mathrm{O}_{2}$. J. Power Sources 364, 33-40 (2017).

36. Luo, Y.-R. Comprehensive Handbook of Chemical Bond Energies (CRC Press, Boca Raton, 2007).

37. Li, B. et al. Manipulating the electronic structure of Li-rich manganese-based oxide using polyanions: towards better electrochemical performance. $A d v$. Funct. Mater. 24, 5112-5118 (2014).

38. Li, B., Yan, H., Zuo, Y. \& Xia, D. Tuning the reversibility of oxygen redox in lithium-rich layered oxides. Chem. Mater. 29, 2811-2818 (2017).

39. Liu, J. T. et al. The effect of boron doping on structure and electrochemical performance of lithium-rich layered oxide materials. ACS Appl. Mater. Interfaces 8, 18008-18017 (2016).

40. Nakamura, T. et al. Defect chemical studies on oxygen release from the Li-rich cathode material $\mathrm{Li}_{1.2} \mathrm{Mn}_{0.6} \mathrm{Ni}_{.2} \mathrm{O}_{2-\delta}$. J. Mater. Chem. A 7, 5009-5019 (2019).

41. Eshetu, G. G. et al. Electrolytes and interphases in sodium-based rechargeable batteries: recent advances and perspectives. Adv. Energy Mater. 10, 2000093 (2020).

42. Zhang, X. D. et al. Suppressing surface lattice oxygen release of Li-rich cathode materials via heterostructured spinel $\mathrm{Li}_{4} \mathrm{Mn}_{5} \mathrm{O}_{12}$ coating. Adv. Mater. 30, 1801751 (2018).

43. $\mathrm{Hu}, \mathrm{E}$. et al. Evolution of redox couples in Li- and Mn-rich cathode materials and mitigation of voltage fade by reducing oxygen release. Nat. Energy 3 , 690-698 (2018).

44. Raccichini, R., Varzi, A., Wei, D. \& Passerini, S. Critical insight into the relentless progression toward graphene and graphene-containing materials for lithium-ion battery anodes. Adv. Mater. 29, 1603421 (2017).

45. Obrovac, M. N. \& Chevrier, V. L. Alloy negative electrodes for Li-ion batteries. Chem. Rev. 114, 11444-11502 (2014).

46. $\mathrm{Li}$, Y. et al. Air-stable copper-based $\mathrm{P} 2-\mathrm{Na}_{7 / 9} \mathrm{Cu}_{2 / 9} \mathrm{Fe}_{1 / 9} \mathrm{Mn}_{2 / 3} \mathrm{O}_{2}$ as a new positive electrode material for sodium-ion batteries. Adv. Sci. 2, 1500031 (2015).

47. Zhang, B. et al. Insertion compounds and composites made by ball milling for advanced sodium-ion batteries. Nat. Commun. 7, 10308 (2016).

48. Zhou, Y.-N. et al. A P2/P3 composite layered cathode for high-performance Na-ion full batteries. Nano Energy 55, 143-150 (2019).

49. Yuan, D. D., Wang, Y. X., Cao, Y. L., Ai, X. P. \& Yang, H. X. Improved electrochemical performance of Fe-substituted $\mathrm{NaNi}_{0.5} \mathrm{Mn}_{0.5} \mathrm{O}_{2}$ cathode materials for sodium-ion batteries. ACS Appl. Mater. Interfaces 7, 8585-8591 (2015).

50. Lyu, Y. et al. An overview on the advances of $\mathrm{LiCoO}_{2}$ cathodes for lithium-ion batteries. Adv. Energy Mater. 10, 2000982 (2020).

51. Zhang, S. S. Problems and their origins of Ni-rich layered oxide cathode materials. Energy Storage Mater. 24, 247-254 (2020).

52. Xie, Y. et al. In operando XRD and TXM study on the metastable structure change of $\mathrm{NaNi}_{1 / 3} \mathrm{Fe}_{1 / 3} \mathrm{Mn}_{1 / 3} \mathrm{O}_{2}$ under electrochemical sodium-ion intercalation. Adv. Energy Mater. 6, 1601306 (2016).

53. Okumura, T., Yamaguchi, Y. \& Kobayashi, H. X-ray absorption near-edge structures of $\mathrm{LiMn}_{2} \mathrm{O}_{4}$ and $\mathrm{LiNi}_{0.5} \mathrm{Mn}_{1.5} \mathrm{O}_{4}$ spinel oxides for lithium-ion batteries: the first-principles calculation study. Phys. Chem. Chem. Phys. 18, 17827-17830 (2016).
54. Wang, Y. et al. Ultralow-strain Zn-substituted layered oxide cathode with suppressed P2-O2 transition for stable sodium ion storage. Adv. Funct. Mater. 30, 1910327 (2020).

55. Kresse, G. \& Joubert, D. P. From ultrasoft pseudopotentials to the projector augmented-wave method. Phys. Rev. B 59, 1758-1775 (1999).

56. Perdew, J. P., Burke, K. \& Ernzerhof, M. Generalized gradient approximation made simple. Phys. Rev. Lett. 77, 3865-3868 (1996).

57. Jain, A. et al. Formation enthalpies by mixing GGA and GGA+Ucalculations. Phys. Rev. B 84, 045115 (2011).

\section{Acknowledgements}

This work was supported by the National Key R\&D Program of China (Grant No. 2019YFA0705600), the Basic Science Center Project of National Natural Science Foundation of China (Grant No. 51788104), the National Natural Science Foundation of China (Grant Nos. 51772301, 22075299, 21975266, and 22005315), the "Transformational Technologies for Clean Energy and Demonstration”, Strategic Priority Research Program of the Chinese Academy of Sciences (Grant No. XDA 21070300). The authors acknowledge Prof. Fuyi Wang and Jilin Tang for conducting ToF-SIMS test and analysis at ICCAS.

\section{Author contributions}

Y.-G.G. proposed and supervised the project. Y.-J.G., Y.-X.Y. and Y.-G.G. designed the experiments. Y.-J.G., P.-F.W. and Y.-B.N. carried out the experimental study. Q.L. and X.Y. performed the XAS experiments. Y.Y. and X.L. performed the DEMS measurements. W.-P.C. performed the XPS experiments. X.-D.Z., M.F., Q.-H.M. and S.X. and other authors all participated in the analysis of the experimental results.

\section{Competing interests}

The authors declare no competing interests.

\section{Additional information}

Supplementary information The online version contains supplementary material available at https://doi.org/10.1038/s41467-021-25610-7.

Correspondence and requests for materials should be addressed to Y.-X.Y. or Y.-G.G.

Peer review information Nature Communications thanks Faxing Wang and the other anonymous reviewers for their contribution to the peer review of this work.

Reprints and permission information is available at http://www.nature.com/reprints

Publisher's note Springer Nature remains neutral with regard to jurisdictional claims in published maps and institutional affiliations.

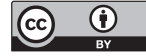

Open Access This article is licensed under a Creative Commons Attribution 4.0 International License, which permits use, sharing, adaptation, distribution and reproduction in any medium or format, as long as you give appropriate credit to the original author(s) and the source, provide a link to the Creative Commons license, and indicate if changes were made. The images or other third party material in this article are included in the article's Creative Commons license, unless indicated otherwise in a credit line to the material. If material is not included in the article's Creative Commons license and your intended use is not permitted by statutory regulation or exceeds the permitted use, you will need to obtain permission directly from the copyright holder. To view a copy of this license, visit http://creativecommons.org/ licenses/by/4.0/.

(C) The Author(s) 2021 